\title{
Parent to Parent Programs: Parent Preferences for Supports
}

\begin{abstract}
Parent to Parent programs facilitate connections between parents who bave young children with special needs by carefully matching an experienced parent in a one-to-one relationship with a parent newly referred to the program. Using national survey results, this article examines the preferences referred parents have for various kinds of emotional and informational supports provided through Parent to Parent programs and the impact of the child's age and severity of disability on parental preferences. Parents preferred a wide range of supports, with the child's age and severity of disability concributing to differences in their preferences. Supports to families must, therefore, be individualized and responsive to child and family characteristics. Key words: mentor parents, mutual sulpport, parental preferences for support, parent support, Parent to Parent
\end{abstract}

\section{Betsy Santelli, MEd}

Coordinator

Parent to Parent Projects

Beach Center on Families and Disability

\section{Ann Turnbull, EdD \\ Professor of Special Education \\ Codirector \\ Beach Center on Families and Disability \\ Iniziersity of Kankas}

Julte Sergeant, MEd

Community Senice Project Manager

Lawrence Public Schools

Estber P. Lerner, MS

Data Management Coordinator

Scbiefelbuscb Institute for Life Span Studies

University of Kansas

Janet G. Marquis, $P b D$

Director of Research Design and Analysis Unit Scbiefelbuscb Institute for Life Span Studies

University of Kansas

Laurence, Kansas
$A$ S SERVICES FOR supporting families of young into public policy and recognized as core components of quality early intervention programs, service providers are working to provide individualized responsive services for families with diverse needs. Parent to Parent programs offer a unique model for accomplishing this goal.'

Parent to Parent programs match a veteran parent-someone wit] experience as a parent of a child with a disability-with a relencd parentsomeone with a child with a similar disability who would like support from a parent who has ubeen there. Common experiences form the basis of a one-to-one relationship in which the referred and veteran parents artange their own supportive interactions. The veteran parent typically shares information and provides emotional support to the referred parent in a one-to-one match that usually lasts from 1 to 6 months.'

The main zoals of the Parent to Parent match are:

- to provide parents with emotional support and understanding, and

- to provide parents with informational suppor about disability and services. ${ }^{1-3}$

Well-escablished programs may offer additional services beyond the one-to-one match, such as a 24-hour telephone line, meetings for group support, training to become a veteran parent, social

Inf Young Cbildren 1996; $X(1): 53-62$

- 1996 .tspen Publishers, Inc. 
events, newsletcers and brochures, advocacy craining, and accivities for other families members. ${ }^{1.2}$

Parent to Parent programs, by their very nacure. respond directly to individual needs, providing services that family members consider imporant, as one mother attests:

Parent to Parent has been my lifeline. When I first heard the diagnosis. I was devastated. Well-meaning doctors and nurses, as well as friends and families, simply did nor understand. It was only when I finally connected with another parent through the Parent to Parent program that I could begin to hope for a future for us all. wly veceran parent was gently there for me whenever I needed her

Child and family characteristics, such as the age of the child who has a disability, the rype and severity of the disability, family size and form, ethnicity, educational background, socioeconomic starus, and geographic location, typically form the basis of the one-to-one match between veteran and referred parents. ${ }^{2+}$ Child and family characteristics will also affect family needs and preferences for support. ${ }^{3.6}$

The age of the child with a disability may affect ianily preferences for support. Families who learn of their child's disability at or shortly after birth deal with a whole host of feelings. At the same time, these parents are having to deal with all of the new procedures and terminology related to their child's disability or special health need. Emotional and informational suppor for obtaining an accurate diagnosis, finding services, informing family and friends, addressing the stigma, and meeting the needs of siblings are frequently mentioned as needs by parents of young children with disabilities: ${ }^{7-10}$

By the time a child with a disability is of school age, the issues that families face often relate to the individualized education plan (IEP) and inclusion in school and community activities. 3.11 Parents at this stage may need informational suppor regarding their educational and legal rights, adaptations of the school curriculum, and strategies for their child to establish friendships. ${ }^{12}$

The severity of the family member's disability may also affect family preferences for support. Mochers of children with severe disabilities may prefer support related to meeting the needs of other family members, while morhers of children with mild or moderate disabilities prefer support directed to meeting the needs of the child with a disability. ${ }^{13}$ Some parents of children with mild disabilities may experience mixed feelings of confusion, frustration, relief, guilt upon receiving the diagnosis, and uncertainty about future dependency or independence when a child's progress is irregular, and they may prefer supports to help them deal with their feelings."

There is a need for further information about whecher and how preferred services vary with individual family characteristics and how services can be designed with parental preferences in mind. The October, 1995 issue of Infants and Young Cbildren included an article reporting the results of a national survey of Parent to Parent programs. Special focus was on veteran and referred parents who participate in Parent to Parent programs, the supports provided to referred parents, and the training provided to veteran parents. This article, an expansion of that Parent to Parent overview, provides answers to the following two questions:

1. What is the impact of the age of the child with a disability on parental preferences for supports offered by Parent to Parent programs?

2. What is the impact of the severity of the child's disability on parental preferences for the supports offered by Parent to Parent programs?

\section{METHOD}

Data were gathered through the national survey of Parent to Parent programs and participating parents conducted by The Beach Center on Families and Disability at The University of Kansas.' The survey for referred parents targeted a random sample of parents from 190 of the Parent to Parent programs participating in the national survey. Seven hundred and four surveys were requested by referred parents; and 240 surveys, representing a conditional return rate of $34 \%$, from 115 different Parent to Parent programs in 43 different states were returned.

The survey for referred parents provided demographic data and detailed information on the actual 
support and services received and preferred by referred parents. Referred parents responded to 46 questions, including three questions on the types of supports received and preferred. Survey respondents were provided wich a listing of seven informational suppors, 11 emotional supports, and 18 other supports. They were asked to note which supports were provided to them and which of the supports they preferred for meeting their needs. Parents were instructed to write the item number corresponding to their preferred supports in boxes labeled most important, second most important, or third most important. For the purposes of this study, first, second, and third choices indicated a preferred support. A more detailed description of the questionnaire and sampling methodology for the current study can be found in the 1995 Infants and Young Children aricle.

\section{RESULTS}

Of the 240 referred parents returning surveys, $161(6 \% \%)$ were parents of children aged birth to 5 years, while $72(30 \%)$ refersed parents had children 6 years and older ( 7 parents, had missing daca). ${ }^{1}$ of the referred parents of children birth to 5, 51 (32\%) reported their child to have a mild disability, 61 $(38 \%)$ a moderate disability, and $39(24 \%)$ a severe disability; $10(6 \%)$ fell in a category of other. Of the referred parents of children 6 and older, $20(28 \%)$ reported their child to have a mild disability, 29 (40\%) a moderate disability, and $23(32 \%)$ a severe disability.

Survey results provided information about the types of emotional, informational, and other program supports that all referred parents preferred. For the current study, the preferences for support were divided into subgroups by the family characteristics of age of child with a disability and the severity of the disability.

\section{Preferred supports by age of child with a disability}

Referred parent responses svere grouped by the family characteristic of age of the child into categories of parent of a young child (birth to 5 years) and parent of an older child ( 6 years and older). Parencal preferences for emotional and informational suppors and program supports beyond the match by age of the child are presented in Table 1.

As can be seen in Table 1, some types of support are valued by parents at any time in the life of their child with special needs, while others are preferred more ofien by parents of younger or older children. A sizeable majority of all of the parents, regardless of the aze of their child with a disability ( $66 \%$ of parents of younger children and $67 \%$ of parents of older children), ranked having someone to listen and understand as a preferred emotional support, suggesting that an understanding listener is helpfu! at any time. However, rwo emotional supports (ie, help in feeling less alone and problem-solving suppor) were preferred by more (greater than 8 percentage points) parents of older children than parenus of younger children.

Four types of informational support were most important to a large number (over $46 \%$ ) of referred parents, regardless of the age of their child with a disability (see Table 1):

1. receiving information about the disability,

2. living with and caring for the child,

3. finding and getting the best possible help for the family member with a disability (advo(acy), and

4. information about community resources and services for the family.

Group meetings, either for emotional or educational support, were preferred by a large percentage (at least $48 \%$ ) of parents of both younger and older children with disabilities. Parental preferences for each of the other program activities beyond the match did not differ by more than 6 percentage points for parents of younger children and parents of older children.

\section{Prefersed supports by severity of disability}

Responses were grouped by the family characteristic of severity of disabilicy into categories of mild, moderate, or severe, according to the severity of disability of the child as reported by the referred parent completing the survey. Table 2 presents parencal preferences for emotional and informa- 
Table 1. Parenc preferences for supports by age of child

\begin{tabular}{|c|c|c|}
\hline Supports & $\begin{array}{c}\text { Birth- } \\
5 \text { years } \\
N=161\end{array}$ & $\begin{array}{c}6 \text { years } \\
\text { and older } \\
N=72\end{array}$ \\
\hline Ecorional supports & $N=155$ & $N=70$ \\
\hline $\begin{array}{l}\text { Someone to listen and } \\
\text { understand }\end{array}$ & $66 \%$ & $67 \%$ \\
\hline Knowledge of others & & \\
\hline who are doing $O K$ & $39 \%$ & $26 \%$ \\
\hline Hope for the fucure & $32 \%$ & $30 \%$ \\
\hline $\begin{array}{l}\text { Help in feeling less } \\
\text { sone }\end{array}$ & $30 \%$ & $42 \%$ \\
\hline Ways to deal with & & \\
\hline stress & $23 \%$ & $28 \%$ \\
\hline $\begin{array}{l}\text { Dealing with the } \\
\text { diagnosis }\end{array}$ & $20 \%$ & $24 \%$ \\
\hline Problem-solving & & \\
\hline support & $16 \%$ & $27 \%$ \\
\hline Informational supports & $N=157$ & $N=69$ \\
\hline Disability information & $65 \%$ & $59 \%$ \\
\hline $\begin{array}{l}\text { Caring for child } \\
\text { Ways to find and }\end{array}$ & $61 \%$ & $52 \%$ \\
\hline get services & $54 \%$ & $55 \%$ \\
\hline Communicy resources & $48 \%$ & $46 \%$ \\
\hline Financial information & $19 \%$ & $25 \%$ \\
\hline Tespite care information & $15 \%$ & $20 \%$ \\
\hline Other prosam & & \\
\hline supports & $N=126$ & $N=58$ \\
\hline $\begin{array}{l}\text { Group meetings for } \\
\text { emorional suppor }\end{array}$ & $48 \%$ & $50 \%$ \\
\hline Group meetings for & & \\
\hline education & $44 \%$ & $50 \%$ \\
\hline 24-hour $\mathrm{warm}$ line & $25 \%$ & $29 \%$ \\
\hline Social events & $24 \%$ & $22 \%$ \\
\hline Activities for other & & \\
\hline family members & $12 \%$ & $7 \%$ \\
\hline
\end{tabular}

tional supports and the program supports beyond the match, according to the level of severity of the disability of the child.

At least $61 \%$ of all parents ranked having someone to listen and understand as important, regardless of the severity of their child's disability; and at least one-chird of all parents ranked help in feeling less alone as important regardless of the severity of their child's disability. As can be seen in Table 2, receiving information about the disability was important to the greatest percentage $(74 \%)$ of parents whose children have mild disabilities and the grearest percentage (62\%) of parents of children with noderate disabilities. The greatest percencage of parents of children with severe disabilities $(63 \%)$ ranked information about living with and caring for the child as the most preferred rype of support. Information about respite care and financial assistance were preferred by $32 \%$ of parents of children with severe disabilities, compared to less than $15 \%$ of parents of children with mild disabilities.

The greatest percentage of all parents, regardless of the severity of their child's disability, reported that group meetings for either emotional or educational support were important. More than twice as many parents of a child with a severe disability ranked a telephone warm-line as important, as compared to parents of children with mild disabilities (38\% and $18 \%$, respectively).

\section{Preferred supports by age of child and severity of disability}

Table 3 presents information on the parental preferences for emotional and informational supports and other program supports beyond the match, as determined both by the age of the child and the severity of the disability. As can be seen in Table 3, over half of all parencs ranked the emocional support of having someone to listen and understand as important, regardless of the age of their child and the severity of their child's disability.

The greatest differences in how parents ranked the emotional supports provided by Parent to Parent programs often existed between parents of young children with mild disabilities and parents of young children with severe disabilities. Two emotional supports-dealing with stress and problemsolving support-were ranked as important by almost twice as many parents of young children with severe disabilities as by parents of young children with mild disabilities.

Whether the child's disability is mild or severe appears to have less of an effect on the preferences of parents of older children for emotional suppors. With the exception of the emotional support of gaining an awareness that there are orher families who are doing OK (ie, $15 \%$ of parents of children 
Table 2. Parent preferences for supports by severity of disability of chiid

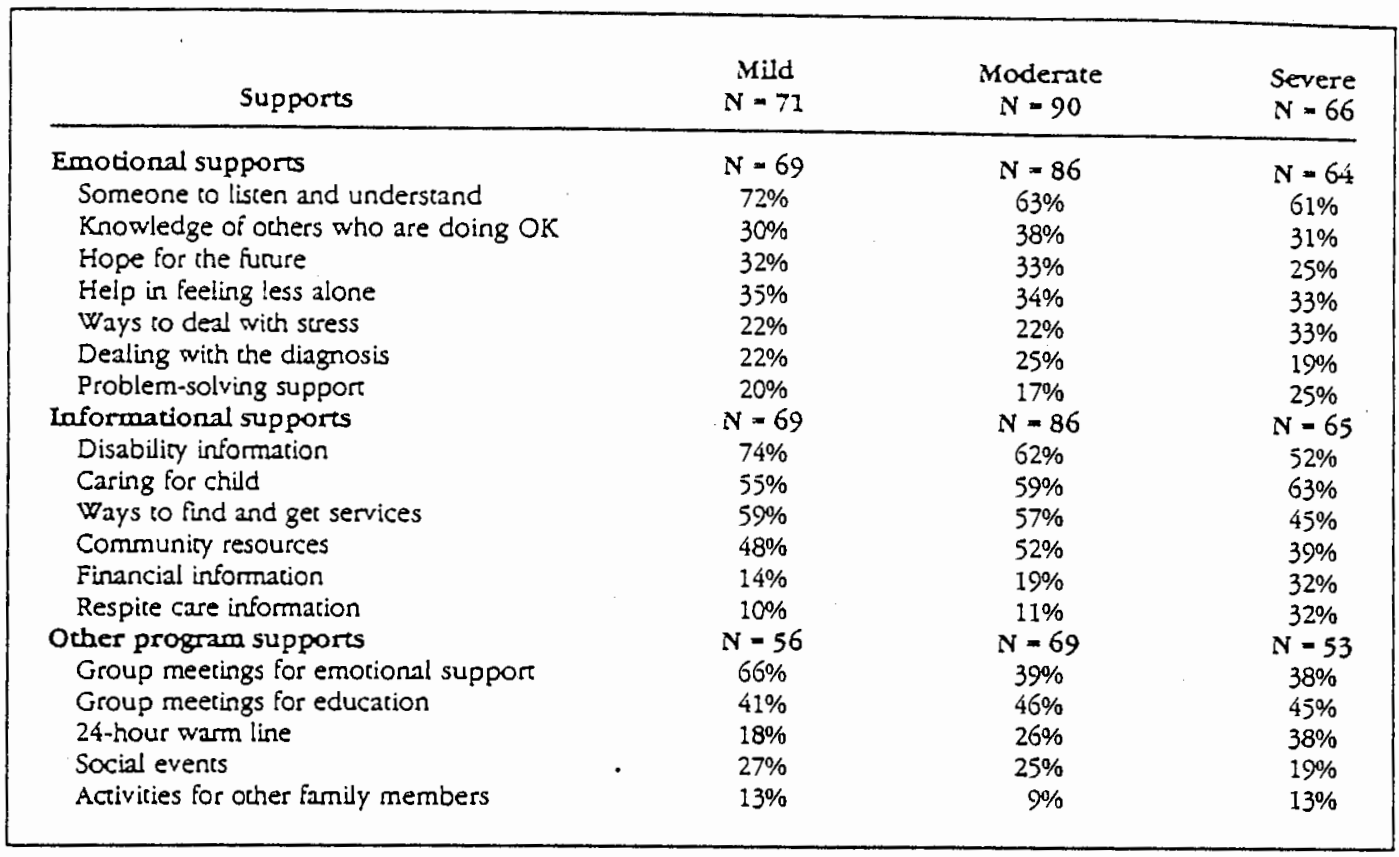

with miid disabilicies ranked this support as important, whereas $27 \%$ of parents of children with severe disabilities preferred this support) and the emotional suppor of finding ways to deal with stress (35\% of parenus with mild disabilities ranked this support as important, whereas $46 \%$ of parents with severe disabilities preferred this support), there were no ocher supports that had a greater chan 10 percentage point discrepancy in rankings between parencs of children with mild and severe disabilities.

The data reveal some interesting similarities and differences in parental preferences over time. As seen in Table 3, some supports are preferred regardless of the age of the child and the severity of the child's disability (ie, having someone to listen and understand, information about the disability and how to care for the child, as well as information about services and community resources). Group meetings for emotional and/or educational support are valued by a sizeable percentage (ie, at least $30 \%$ ) of all parents regardless of the age and severity of disability of their child. It is also inceresting to nore chat at least one-third of the parents who have a child with a severe disability ranked information about respite care and financial assistance as preferred regardless of the age of their child.

While some preferences appear to remain relatively constant over time, it is interesting to note in Table 3 that parents who have children with mild disabilities generally reported greater differences in their preferences as the child gers older than did parents of children with severe disabilities, whose preferences remained more constant over time.

\section{DISCUSSION}

The rvide range of supports considered important by referred parents suggests that when Parent io Parent programs (and ocher family support providers) offer a continuum of supports, parents are able to individualize their Parent to Parent experience. Understanding the differences in chese preferences for support based upon age and severity of disability 


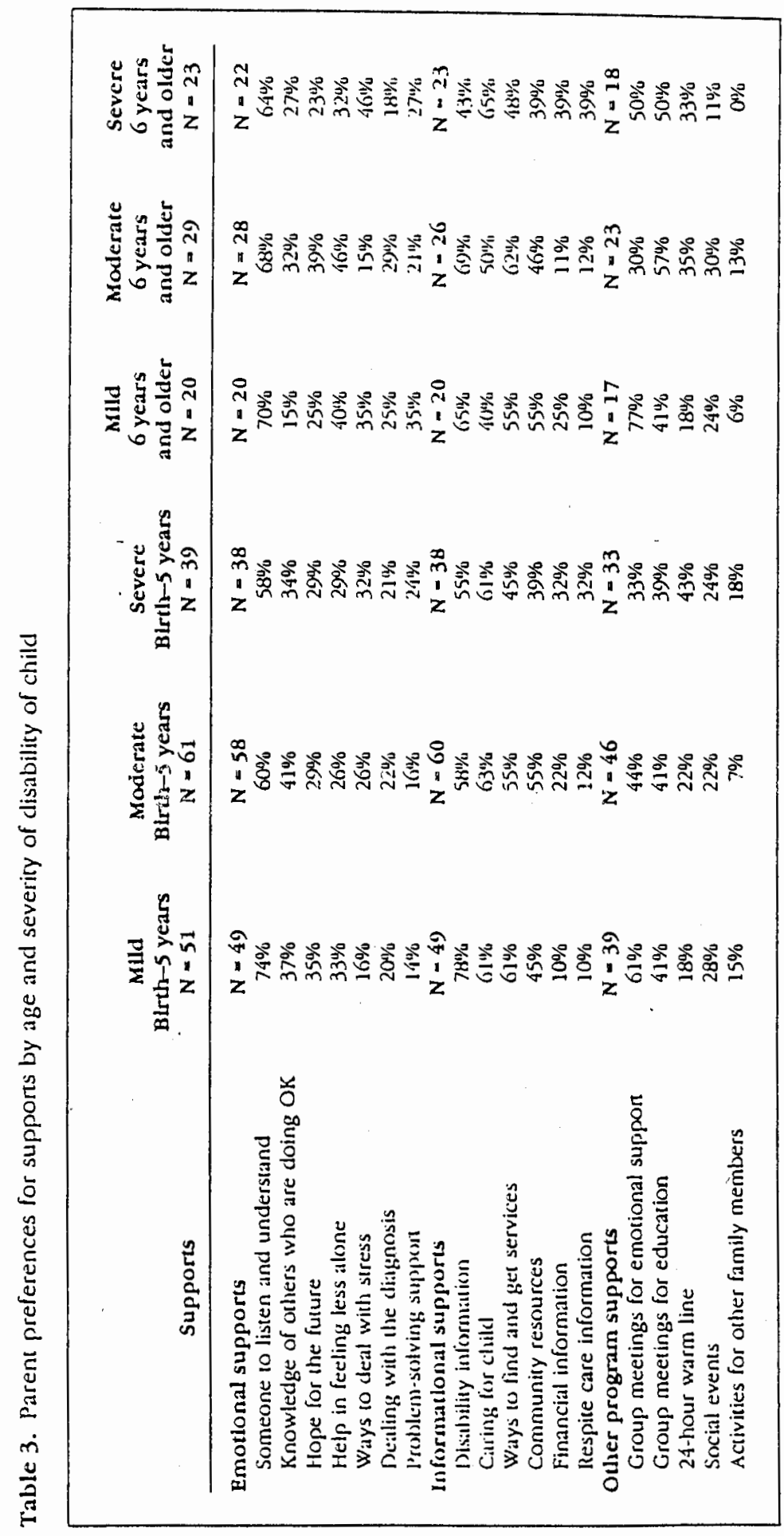


of the child wil! help individuals who are developing a Parenc to Parent program and/or other family support effort to prioritize and modify the services provided. A discussion of these differences and some implications for parents and service providers of these parenc preferences are presented.

\section{Preferred supports by age of child with a disability}

A one-to-one Parent to Parent match provides a referred parent with an opportunity to talk with a veteran parent--someone who can listen and understand based upon their own similar family and disability experiences-and this type of support was by far the preferred type of emotional support available in Parent to Parent programs regardless of the age of the child. This corroborates the findings of previous studies of Parent to Parent programs, 3.4 .14 and suggests that Parent to Parent programs are indeed meeting a preferred need.

While the literature suggests that feelings of isolation and loneliness often accompany the birth of a child with a disability, ${ }^{3.15,16}$ it is inceresting to note that, while parencs of younger children frequendy mention their preference for help in feeling less alone, parents of older children actually have greater preferences for this type of support. Dealing with feelings of isolation apparently continues to be an issue for these parents of older children, and professionals providing services to families who have older children with special needs should be aware of that long-term need.' A single parent of a 9-year-old boy with autism explains:

Even though I have received lots of information about autism from many different professionals, until I connected with Parent to Parent I had not had an opportunity to calk to another parent who shared my experiences, my frustrations, and, yes, my special joys. I fett very alone with my feelings.

As children with disabilities move into the school system, parents often face a whole host of new decisions in a system that is not as family-centered as in early intervention programs."11 Given the expansion of the family's environment and less support from the system, it is perhaps not surpris- ing that more parents of oider children preferred problem-solving support than did parents of younger children.

Parents, regardless of the age of their child with a disability, are searching for informacion abour the disability, community resources and services, how to find and get help, and living with and caring for their child. The fact that these four different kinds of informational supports were ranked as preferred by almost half or more of all parents suggests that the need for these types of information remains across the lifespan.

The importance of group meetings, both for emotional and educational support, for parents of both younger and older children with disabilities suggests that some parents appreciate opporiunities to connect with other parents in a group setting, regardless of the age of their child. While Parent to Parent programs are founded on the basis of the one-to-one match between two parents, $84 \%$ of the programs aiso provide group activities for support to respond to these parental preferences. ${ }^{1.2}$

\section{Preferred supports by severity of disability}

Just as the age of the child with a disability has very litcle impact on how strongly parents seem to prefer the emotional support of having someone to listen and understand, so too, the severity of the child's disabilicy does not seem to influence parental preferences for this support. While some support exists in the literature that parents of children with severe disabilities experience higher levels of stress, ${ }^{17,18}$ and it might, therefore, be assumed that parents of children with severe disabilities_would have a greater need for this type of support than would parents of children with mild disabilities, the current findings do not support this assumption. Parents of children with disabilities of all severity levels value the opportunity to talk with someone who shares their experiences.

With respect to preferences for informational supports, it is interesting to note that, while a large percentage of all parents regardless of the severity of their child's disability prefer receiving information about 
- the disability,

- finding and getting help, and

- community resources,

fewer parents of children with severe disabilities preferred these kinds of information. These differences may again be related to the fact that a more severe disability may come with more information for the parents about the disability itself and about available services.

Living with and caring for a child with a severe disability often requires expensive equipment and monitoring and caregiving 24 hours every day. ${ }^{19}$ It is, therefore, not surprising that there are significant differences in the preferences of parents for information about respite care and financial assistance based on the severity of the child's disability. Information about how to get time away from childcare responsibilities and money to pay for required services and equipment is an important support, especially for parents of children with severe disabilities. A father of a 3-year-old daughter whose disability requires total care related:

It is very difficult for us to ever find a chance to spend time just with each other-cone of us is always on dury, ind only one of the many babysitters we had for our older children is comfortable sitting for us now-the additional carecaking responsibilities for our 3 year oid are too incimidating. Respite care is an option, but it is in very shor supply, and you have to plan for it way in advance. The spontaneity in our relationship has just vanished.

Just as parents of children of all ages mentioned their preferences for group activities in large numbers, so too, group activities were also preferred by large percentages of parents regardless of the level of severity of the child's disability.

\section{Preferred supports by age of child and severity of disability}

As might be expected, when age and severity of disability are combined, many of the same parental preferences are apparent as when age and severity of the disability are considered separately. By noting which emotional, informational, and other program supports are preferred by all parents

regardless of the age and severity of the disability of the child, coordinators of newly developing Parent to Parent programs, as well as ocher service providers building family support programs, will be able to prioritize program components to be developed.

Those program supports that were mentioned as preferred by at least $30 \%$ of all parents regardless of the age and severity of the disability of the child include:

- emotional support-having someone to listen and understand,

- information support-having information about the disability, finding and getting services, living with and caring for the child, accessing community resources, and

- other program supports-having group meetings for either emotional or educational support.

Parents and/or professionals interested in establishing a Parent to Parent program and service providers working with families who have children with special needs may want to be sure that their programs support the existence of these particular suppors for parents.

It is also interesting to note that many of the informational supports received similar rankings over time by parents, with the severity of the disability having only a minimal impact-suggesting that parents' need for information remains relatively stable. Those developing Parent to Parent programs and other family support programs should be prepared to provide basic information about a wide range of disabilities and to access sources that provide more detailed disability information for those families desiring this depth of information. Providers of services to children with special needs and their families should also acquaint themselves with other community services and agencies providing services for persons with disabilities, as well as general community programs for all community residents. Contact with a parent who has first-hand experience including a child with a severe language disability into a museum. 
workshop, knowledge about which fast food restaurant has the easiest accessibility for a wheelchair, or a tip about a gymnastics instructor who knows sign language may encourage parents to involve their children in community programs.

More than crvice as many parents of children with severe disabilities ranked information about financial assistance and information about respite care as preferred suppors than did parents of children with mild disabilities, regardless of the age of the child. Families with children who have severe disabilities often deal with expensive and extensive caretaking responsibilities, ${ }^{19}$ thus making information about financial assistance and respite care opportunities particularly valuable to them. While these sorts of information were ranked as preferred by much smaller percentages of parents of children with mild disabilicies, Parent to Parent and other family support programs that seek to be crossdisability will need to have access to this information in order to meet the needs of all parents.

Parents' preferences for emotional supports showed more variability, boch over time and beinecen levels of severity of the disability. This finding is, perhaps, not surprising given that parents bring their orw set of emotional needs and coping styles to their family situation. Help in dealing with the diagnosis is the one emotional response that does appear to remain relatively stable across time and across severity of the disability. It will be important for providers involved in parent support to recognize that dealing with the diagnosis is not a single effort in time for parents, but rather that parents continue to deal with the diagnosis and its implications throughout the life of the child. ${ }^{\text {s }}$

As Parent to Parent programs grow in response to the needs and preferences of participating parents in their communities, many programs have added a variety of other supports and services. Although Parent to Parent programs revolve around the one-to-one match between veteran and referred parents, group meetings for emotional or educational support were frequently ranked as preferred supports regardless of the age and severity of the disability of their child. Apparently, the sharing of common experiences is also appreciated in a group setting. Contact with several veteran parents and other referred parents may offer some advantages such as exposure to a variety of experiences as a parent of a child with a disability, guidance from parents who have "been there," or emporverment and empathy from other parents whose children are age mates. ${ }^{20}$

In addition to emotional and educational group support, access to a 24-hour telephone warm line was ranked as a preferred support by at least onethird of the parents of children with severe disabilities regardless of the age of their child. It may be that parents of children with severe disabilities prefer a "stay at home" style of support rather than such activities as social events that require all of the logistica! arrangements of preparing and transporting family members. ${ }^{19}$ As Parent to Parent programs mature, the parental preferences for these various other program supports will provide helpful information in prioritizing the development of new program components.

While it is helpful to observe which supports are preferred by the largest percentages of referred parents, an individualized family support program will also consider the supports ranked by a lesser number of parents. Virtually all of the emotional, informational, and other program suppors were ranked by some parents as one of the three most important supports offered by Parent to Parent programs. To these parents, these less popular supports were significant.

Information about the types of support preferred by referred parents in Parent to Parent programs will aid in the planning stages of such programs and in the development of family support activities for parents. While certain types of support are considered by a large number of families to be important, other supports are just as important to a smaller number of families and, thus, should be taken into 


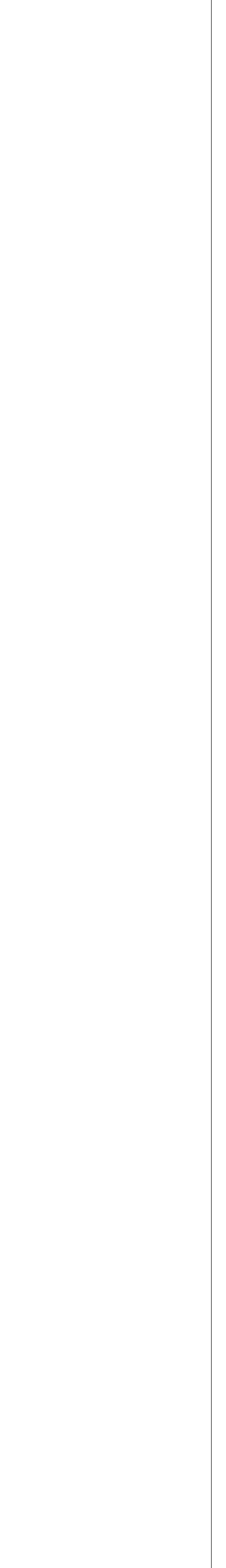


consideration. The wide range of supports that referred parents considered important to their individual situations testifies to the scope of support families need to receive from involvement in Parent to Parent programs and ocher family support efforts. The information gained from this study reinforces the belief that the process of supporting families must be individualized by offering a variety of support options responsive to child and family characteristics.

\section{REFERENCES}

1. Santelli B, Turnbull A, Marquis JG, Lemer E. Parent to Parent programs: a unique form of murual suppor. Inf Young Cotldren. 1995;8(2):48-57.

2. Sancelli B, Turnbull A, Lemer E, Marquis J. Parent to Parent programs: a unique form of mutual support to families of persons with disabilities. In: Singer $G$, Powers L eds. Families Disability, and Empowerment: Active Coping Skills and Strategies for Family Interientions. Balimore, Md: Brookes; 1993.

3. Boukydis $C F$, Lester B, Hoffman J. Parencing and social suppor nerworks in families of $\mathrm{erm}$ and preierm infants. In: Boukydis CF, ed. Research on Support for Parents and infants in the Postratal Period. Norwood, NJ: Ablex Publishing Corporation; 1987.

4. Brookman BA. Parent to Parent: a mode! for parent support and information. Top Early Cbildbood Spesial Educ 1988;8(2):88-93.

5. Tumbull is Tumbull HR. Families, Professionals. and Exceptionality: A Special Parnersibip. New York, NY: Macmillan Publishing Company; in press.

6. Bernheimer LP, Gallimore R, Weisner TS. Ecocultural theory as a contex for the individual family service pian. f Early Intervention. 1990:14(3):219-233.

7. Blacher $J$. Sequential stages of adjustment to the birth of a child with handicaps: fact or artifact? Ment Retard. 1984;22:55-68.

8. Gowen JW. Christy DS, Sparling J. Informational needs of parents of young children with special needs. J Early interventton. 1993;17(2):194-210.

9. Bailey DB, Blasco PM, Simeonsson RJ. Needs expressed by mothers and fathers of young children with disabilities. Am J Ment Retard. 1992;97:1-10.

10. Turbiville VP, Tumbull AP, Garland $C$, Lee IM. Development and implementation of IFSPs and IEPs: Opportunities for empowerment. In: Odom $S$, McLean M. eds. Recommended Practices in Early interiention. Austin, Tex: Pro-Ed; in press.
11. Ervin EJ, Soodak LC. I never knew I could stand up to the system: families' perceptions in pursuing inclusive education. JAssoc Persons urith Severe Handicoos. 1995;20(2):136-1 46.

12. Buswell $B E$, Schaffner $C B$. Families supporting inclusive schooling. In: Stainback W, Stainback S, eds. Suppor Networks for Inclustue Schooling: Interdependent, Integrated Edication. Baltinore, Md: Brookes; 1990.

13. Upshur CC. Mothers' and fachers' ratings of the benefits of early intervention services. J Early Intervention. 1991;15(4):345-357.

14. Santelli B, Turnbull A, Marquis JG, Lemer E. Parent to Parent programs: ongoing support for parents of young adults with special needs. I Vocational Rebabil 1992;3(2):25-37.

15. Kazak AE, Marvin RS. Differences, difficulties and adapeation: stress and social nerworks in families with a handicapped child. Family Relations. 1984;33:67-77.

16. Simons R. After the Tears: Parents Talk About Raising a Cbild With a Disability. New York, NY: Harcourt, Brace, \& Jovanovich; 1987.

17. Bristol MM, Schopler E. Stress and coping in families with autistic adolescents. In: Schopler E, Mesibov GB, eds. Alitism in Adolescents and Adulis. New York, VY: Plenum Press; 1983.

18. Gallagher JJ, Beckman P, Cross AH. Families of handicapped children: sources of stress and its amelioration. Exceptional Cbildren. 1983;50:10-19.

19. Knoll J. Being a family: the experience of raising a child with a disability or chronic illness. In: Brndley V. Knoll J, Agosta JM, eds., Emerging Issues in Family Support. Washingron, DC: Monographs of the AmeriCan Association on Mental Retardation; 1992.

20. Krauss iNW, Upshur CC, Shonkoff JP, Hauser-Cram P. The impact of parent groups on mothers of infants with disabilities. / Early Interiention. 1993;17(1):8-20.

This research was supported by a grant from the National Institute on Disability and Rehabilitation Research to the Beach Center on Disability, Grant \#H133B30070. 